\title{
Water stage component analysis in an estuary using the Hilbert Huang transform
}

\author{
Yen-Chang Chen ${ }^{1}$, Ru-Huei Chen ${ }^{2}$, Su-Pai Kao ${ }^{3, *}$, and Ming-Yi Lin ${ }^{3}$ \\ ${ }^{1}$ Department of Civil Engineering, National Taipei University of Technology, Taipei City, Taiwan \\ ${ }^{2}$ Graduate Institute of Engineering Technology-Doctoral, National Taipei University of Technology, Taipei City, Taiwan \\ ${ }^{3}$ Department of Civil Engineering, National Taipei University of Technology, Taipei City, Taiwan
}

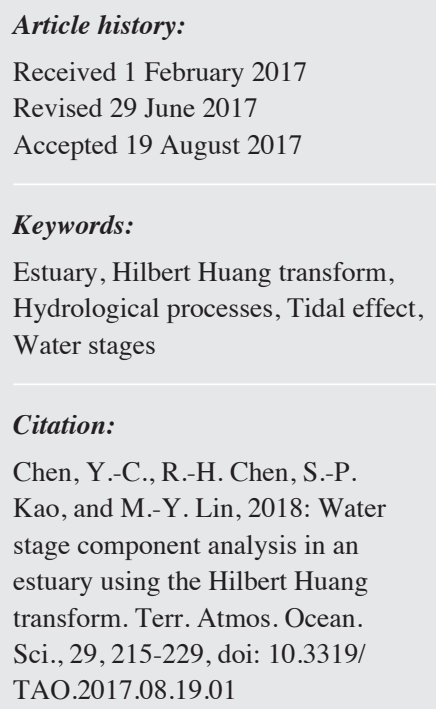

\begin{abstract}
This study applies a novel concept to decompose water stages to understand the factors that affect an estuary. The estuary water stages vary due to different complex, often nonlinear and non-stationary factors. Therefore, it is very difficult for researchers to break down water stages into contributing factors with single integrated methods. The Hilbert Huang transform (HHT) is an easy to use, efficient and powerful method of processing non-stationary, non-linear signals to optimize a complicated data process. The HHT is composed of empirical mode decomposition (EMD) and Hilbert transform. EMD decomposes the water stages into several intrinsic mode functions (IMFs). Through the Hilbert transform, IMFs could obtain amplitude and instantaneous frequency with time. Those IMFs with amplitude and frequency can be used to represent those factors that affect the water stages in an estuary. However, the physical meanings represented by IMFs should be inferred in conjunction with the other hydrological data. This study uses Tanshui River estuary water stages to show HHT applied to determining the factors that affect the water stages. HHT application provides a methodology for others to follow to identify the water stage components in an estuary.
\end{abstract}

\section{INTRODUCTION}

An estuary is a partially enclosed coastal body of brackish water with one or more rivers or streams flowing into it, which also has a free connection to the open sea (Pritchard 1967). Estuaries display unique hydrological processes, with the water stages constantly change under interactions between the riverine and marine factors. The estuary variation in water stage is manifested in flow changes, which are the major drivers for changes in the estuary physical and chemical characteristics. Phenomena such as salinity, pollutant transport, river scour and deposition in estuaries are affected by the flow changes (Pugh 1996; Elliott and McLusky 2002; Prandle 2004; Thain et al. 2004; Vandenbohede et al. 2008; Ganju et al. 2012; Shaha et al. 2012). The causes for variations in water stage are extremely complex, resulting mainly from the interactions among stream flows, ocean tides and other factors (El-Jabi et al. 1992; Godin 1985).

Current approaches classify the impact factors by sea-

\footnotetext{
* Corresponding author

E-mail:spkao@ntut.edu.tw
}

sons, El Niño-Southern Oscillation (ENSO), flushing times (residence time), lunar cycles, storms and river hydrological events, and diurnal tides (Dyer 1973). The ENSO is an oscillating phenomenon caused by fluctuations in oceans and the climate on the earth, which could affect the global precipitation and temperature distribution. Seemingly regular, but without a particular frequency, the ENSO phenomenon influences the physical and chemical mechanisms of a tidal river such as salinity, the exchanges and concentrations of chemical substances, and the dynamic behaviors of water (Zeldis et al. 2008; Meccia et al. 2009; Null et al. 2012). Some studies have indicated that estuaries are affected by variations in a river discharge, associated with the ENSO cycles (Marcelo Acha et al. 2008).

Lunar cycles and diurnal tides are also important factors in water stage variations in estuaries. For example, O'Callaghan (2004) reported how estuary water stages in the Swan River, Australia, were affected by the principal ocean lunar diurnal constituent (O1), lunisolar diurnal constituent (K1), principal solar semi-diurnal constituent (S2), 
and principal lunar semidiurnal constituent (M2). A study of the Tanshui River in Taiwan by Chen et al. (2013) found that the Tanshui River Estuary is influenced mainly by the principal ocean lunar semidiurnal constituent (M2).

Storms and river hydrological event can also impact the water stage in estuaries. The hydrological characteristics of the river flow, such as precipitation, and geographic features such as the shape of the catchment area and river density, could cause changes in the water stage and discharge of tidal rivers (Liu 2005; Chen et al. 2012).

From these studies, we know the water stage components in an estuary include seasons, El Niño-Southern Oscillation (ENSO), flushing times (residence time), lunar cycles, storms, river events, and diurnal tides... etc.

Due to the adaptability in non-linear and non-stationary data, the HHT can be used for geophysical researches. Based on former researches (Huang and Wu 2008; Rao and Hsu 2008; Chen et al. 2014), we make use of HHT to decompose the water stage in the estuary. The HHT is used in geophysical researches and also in mechanical inspection (Yan and Gao 2006), financial analysis (Huang et al. 2003), turbulent flow and structural inspection measurement (Huang and Attoh-Okine 2005; Huang and Shen 2014).

The estuary water stage is one of the major influential factors for the evolving estuary. The water stage components in an estuary could be determined using various methods each of which must be derived from complex calculations or by qualitative methods. This study proposes a method using only one algorithm to analyze water-stage components in an estuary. The advantages of the proposed method include algorithm flow simplification, algorithm Integration, and the capability to perform water stage component quantitative analysis in an estuary.

\section{HILBERT HUANG TRANSFORM}

A water stage hydrograph could be conceptualized as analog signals. Through the signal processing procedures, original signals can be categorized or used to separate the desired information via various analytical methods.

The most sophisticated signal processing method is the Fourier transform. It is a linear and integral transform dealing with signals between the time and frequency domains. Especially for periodic signals, the Fourier transform performance is very good. Figure 1 shows the water stage hydrograph for an estuary at different time periods. Figure 1a includes two typhoon events while Fig. 1b shows none. Both the Fourier transform and Hilbert Huang transform are applied to obtain the energy-frequency relationship in Fig. 2.

Figure 2a shows the energy-frequency relationship using the Fourier transform, with two high energy frequencies. The frequency matches the tidal characteristics. However, a former research (Dyer 1973) showed that the water stage is affected by various factors in estuaries. Figure $2 b$ shows the energy-frequency relationship using the Hilbert Huang transform. The energy fluctuations demonstrate the non-stationary characteristics. Therefore, the algorithm should be able to treat both the non-stationary and non-linear data as both are important for decomposing the estuary water stages.

Huang et al. (1998) proposed a new signal processing technique that used two empirical mode decomposition procedures (EMD) and the Hilbert Transform (HT) (Rao and Hsu 2008). In the HHT pre-process procedure, EMD uses a sifting process to decompose the signals into numerous oscillating signals called Intrinsic Mode Functions (IMFs) and a residual signal. Unlike the wavelet and Fourier analysis, EMD does not have a predetermined basis. For example, while the Fourier analysis uses sine and cosine functions to describe the overall data length, EMD directly resolves the original signals. Since the original signal characteristics can be fully reflected, HHT can be used for the non-stationary and non-linear time series study. Additionally, the number of data points for each IMF is the same as the number of original data points, so the original data can be obtained from the total sum of IMFs (Huang et al. 2003; Huang and Wu 2008).

The IMF is defined as a function that satisfies two requirements; first, the number of extreme values in the overall data must match the number of zero crossings or with only one difference. Secondly, the mean value of the maxima envelope and minima envelope should be zero. This prevents unnecessary oscillations resulting from the instantaneous frequency due to non-symmetrical waveforms. To deal with the original non-linear and non-stationary signals, it is necessary to set a maximum and a minimum as restraints. The local characteristic time scale is defined as the time difference between those two extreme signal values. If a signal does not include extreme values but inflection points instead, it is necessary to perform a differential equation to obtain them. The final results are derived from integral calculus. The following example illustrates how a sifting process is applied in an EMD to decompose the multiple cumulative intrinsic mode functions.

For example, Fig. 3a shows the steps for establishing IMF using time series $X(t)$ as an example. Firstly, differentiate the local maximum and local minimum in $X(t)$, then use a cubic spline on the two extreme values to create curves approximating the upper and lower envelopes labelled as $E_{u}(t)$ and $E_{l}(t)$, respectively, as presented in Fig. 3b. Compute the two envelopes to derive a mean value and an average curve as shown in Fig. 3c. The mean value $m(t)$ is

$m(t)=\frac{E_{u}(t)-E_{l}(t)}{2}$

Set a variable $d(t)$ to

$d(t)=X(t)-m(t)$ 

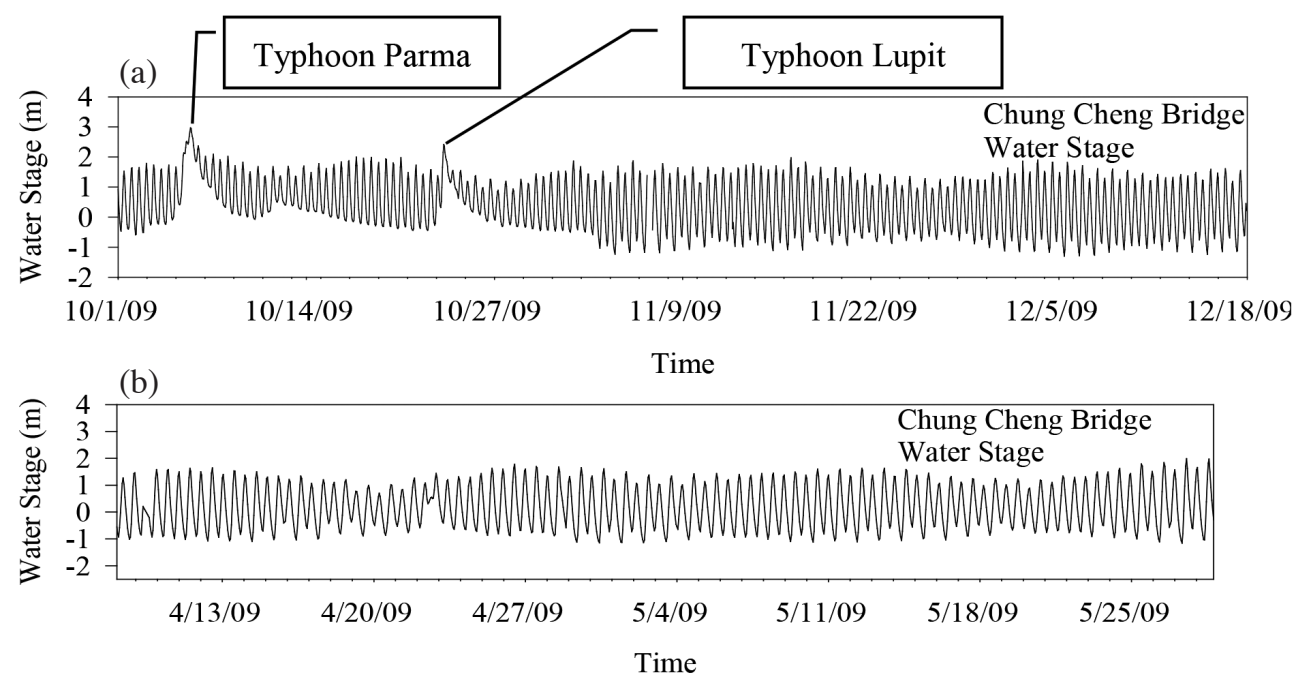

Fig. 1. Water stage hydrograph (a) 0:00 10/1/2009 - 23:00 12/17/2009; (b) 3:00 4/8/2009 - 19:00 5/25/2009.
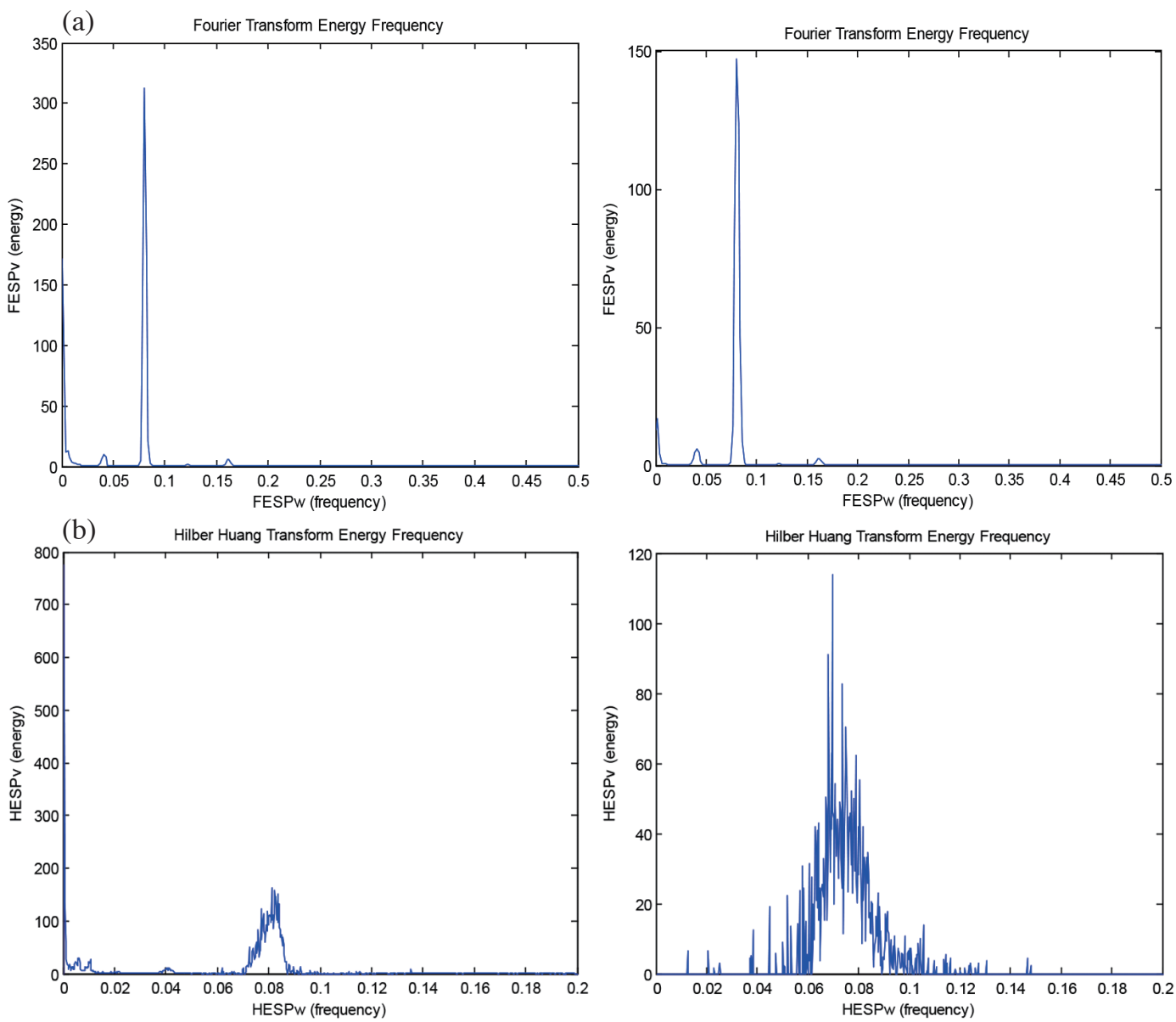

Fig. 2. The energy frequency results at (a) Fourier transform 0:00 10/1/2009 - 23:00 12/17/2009 (left), 3:00 4/8/2009 - 19:00 5/25/2009 (right); (b) Hilbert Huang transform 0:00 10/1/2009 - 23:00 12/17/2009 (left), 3:00 4/8/2009 - 19:00 5/25/2009 (right). 

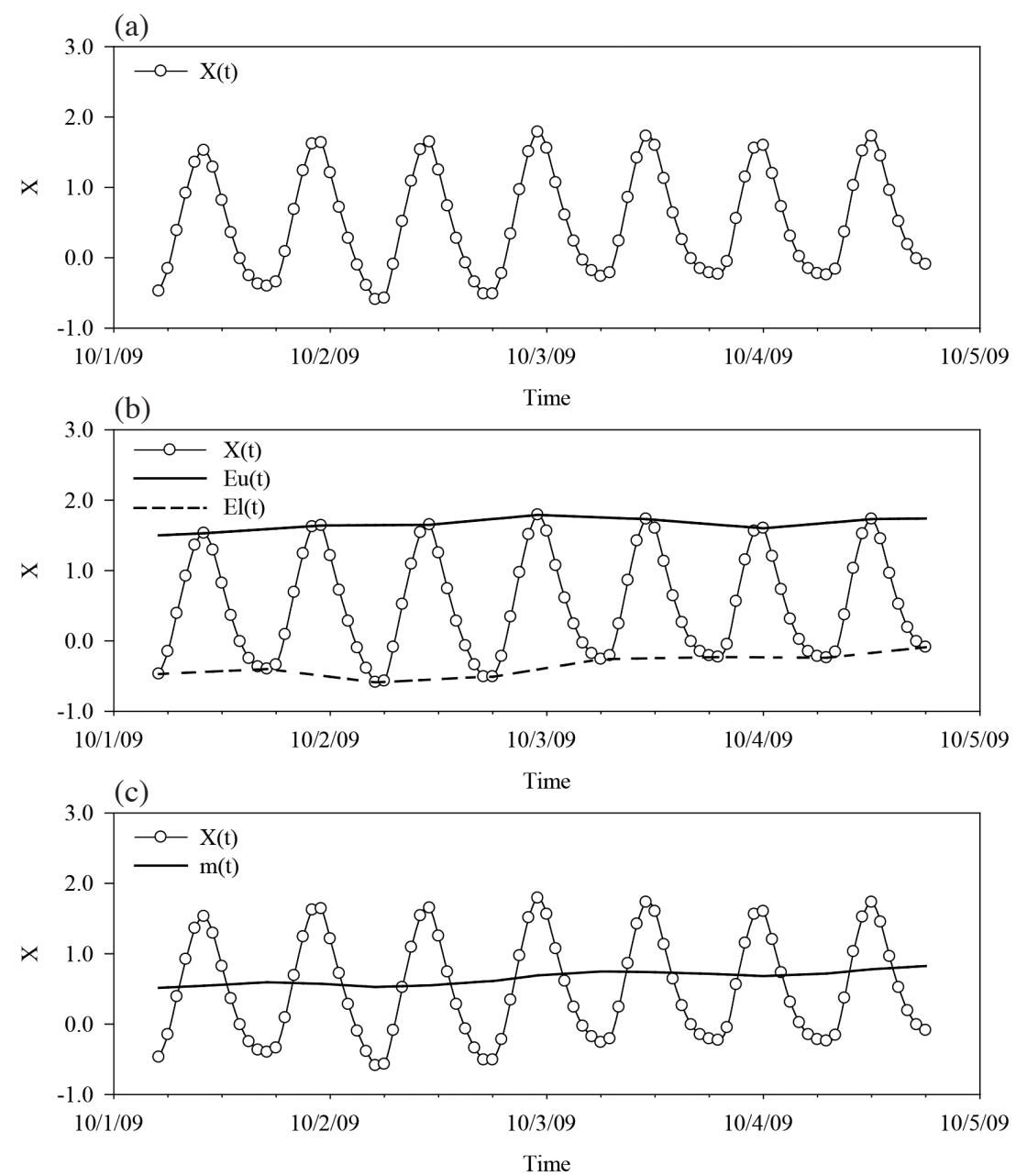

Fig. 3. Definition of sifting; (a) original data (water stage); (b) upper and lower envelopes; (c) local mean value of the envelopes.

where $d(t)$ is the difference between $X(t)$ and $m(t)$. If $d(t)$ does not meet the stopping criterion, set $d(t)$ as a new $X(t)$, and repeat the above steps to differentiate the IMF extremes, until $d(t)$ is consistent with the IMF definition and the stopping criterion. The common stopping criteria include a standard deviation, an S number criterion (Huang et al. 2003), and the evaluation function (Rilling et al.2003). If $d(t)$ is set to $d_{1}(t)$ as IMF1 $C_{1}(t)$. Then set $r_{1}(t)$ to $X(t)-d_{1}(t)$ so that $r_{1}(t)$ is consistent with the original IMF2 $C_{2}(t)$ value. Repeatedly apply the above steps to $r_{1}(t)$ until $r_{n}(t)$ meets the IMF requirements.

$d(t)$, which meets the stopping criterion, is set as IMF component $C_{j}(t)$, and its residual $R_{j}(t)$ is the new $X_{j+1}(t)$ shown in the following equation

$R_{j}(t)=X_{j+1}(t)$

Perform the EMD steps to establish IMF; record the n number of IMFs as $C_{j-n}(t)$. The $X(t)$ is the combination of IMF com- ponents $C_{j}(t)$ and $R_{n}(t)$ as shown in the following equation

$X(t)=\sum_{j=1}^{n} C_{j}(t)+R_{n}(t)$

Each IMF component $C_{j}(t)$ has a physical meaning defined by the data obtained in the analysis. The advantages of EMD are its capabilities to retain the physical features of IMF after it has been resolved and to explain the representative physical significance for each resolved IMF.

For time series $X(t)$, its Hilbert transform $Y(t)$.

$Y(t)=\frac{1}{\pi} P \int_{-\infty}^{\infty} \frac{X\left(t^{\prime}\right)}{t-t^{\prime}} d t^{\prime}$

where $P$ is the Cauchy principal value.

The analytic signal, $Z(t)$, can be defined as

$Z(t)=X(t)+i Y(t)=a(t) e^{i \theta(t)}$ 
Where $a(t)=\left[X^{2}(t)+Y^{2}(t)\right]^{1 / 2}$ and $\theta(t)=\tan ^{-1} \frac{Y(t)}{X(t)}$.

Huang et al. (1998) proposed the difference between the Hilbert Huang transform and Fourier transform. By applying the Hilbert Huang transform, the time series $X(t)$ will become

$X(t)=\sum_{j=1}^{n} a_{j}(t) \exp \left[i \int \omega_{j}(t) d t\right]$

where $\omega$ is the instantaneous frequency and

$\omega=\frac{d \theta(t)}{d t}$

Then the Fourier expanded will be

$X(t)=\sum_{j=1}^{n} a_{j} \exp \left(i \omega_{j} t\right)$

The Hilbert Huang transform (HHT) can provide the amplitude and frequency, which is a function of time. Therefore, the Hilbert Huang transform could estimate the instantaneous frequency, amplitude and time. The relation drawing is called a Hilbert amplitude spectrum or Hilbert spectrum $H(\omega, t)$. The Fourier transform can provide the amplitude and frequency, as well. However, the amplitude is not a function of time in the Fourier transform.

Summarily, the IMFs are obtained using Eqs. (1), (2), (3), and (4). The powers and intensity frequency of IMFs are obtained by following Eqs. (5), (6), (7), and (8). The IMF intensity frequencies are then averaged to obtain the average frequency.

In conclusion, HHT is applied to Geophysical Studies. Each IMF component respectively corresponds to a weather storm, a semimonthly tide, a monthly tide or the sea surface temperature (Huang and $\mathrm{Wu}$ 2008; Lu et al. 2016). Therefore, the EMD analysis could resolve estuary water stage data in each independent IMF component in the study. By explaining the physical significance of each component, it is possible to elucidate each physical factor in the estuary water stages.

\section{DESCRIPTION OF STUDY AREA}

The study area, as shown in Fig. 4, is the Tanshui River basin, which is the largest river basin in northern Taiwan. The Tanshui River downstream is classified as a mesotidal estuary (Liu and Huang 2012). The river basin has an annual runoff approximating $7 \times 10^{9} \mathrm{~m}^{3}$ with an estimated watershed area of about $2726 \mathrm{~km}^{2}$. The Tanshui River mainstream flows through the most developed areas in the Taipei metropolitan region where a branch, the Hsintien River, is the main water supply source. Running through the center of the Taipei metropolis, the Hsintien River is also the main areas of flooding caused by typhoons or heavy rains. Serious flooding has flowed into the Taipei subway system caused by Typhoon Nari in September, 2001. This floor cost several casualties and around \$134 million US dollars in damage. Afterward, the Taipei City authority upgraded the pumping stations along the Tanshui River and Keelung River to improve "The Flood Warning System in Taipei Area".

The Tanshui River is composed of three branches - the Keelung River, the Tahan River and the Hsintien River. The Tanshui River leads into the Taiwan Strait, making its downstream reach affected by tides. Chen et al. (2013) indicated that the estuary boundaries of the Tanshui River are the Keelung River at Wudu, the Tahan River at Shinhai Bridge, and the Hsintien River at the Sholan Bridge, as shown in Fig. 4.

We collected water stage data for the Hsintien River at the Chung Cheng Bridge, located within the estuary, $25 \mathrm{~km}$ away from the river mouth and $7.3 \mathrm{~km}$ away from the Hsintien River and Tahan River confluence. This is the key position in the overall Tanshui River basin. The Feitsui Reservoir is at the head water point and the Zhitan Water Purification Plant supplies water for the Taipei metropolitan area. In the downstream region, the flow comes from the two main tributaries, the Hsintien River and the Tahan River. Consequently, the water stage data for this region are an essential reference for planning the water supply system area and estimating the flood warning system in the Taipei Area. The hydrological data obtained from the study area are relatively complete. Two important water stage stations in the upstream region of the Chung Cheng Bridge are the Po Bridge water stage station, located at the Jingmei River, which is about $8 \mathrm{~km}$ upstream of the mainstream, and the Sholan Bridge water stage station, which is located about $4.5 \mathrm{~km}$ upstream from the Chung Cheng Bridge. The Jingmei River is a tributary of the Hsintien River flowing through the Taipei district. It is the most important stream in the southern Taipei district. The Datonshan rain gage station, located on Datonshan Mountain at the most upstream Hsintien River region, measures the rainfall for the region. The analyses in this study included hourly water stage data and hydrological data obtained in the study area, including temperature, pressure, humidity, and rainfall, collected at every water stage station or rain station from 10/01/2009 - 12/17/2009, and from 4/08/2009 - 5/28/2009. Figure 4 shows the gaging stations used in this study. Table 1 shows the statistical data obtained by each hydrological station during Typhoon Parma, Typhoon Lupit and two heavy rain events between October and December, 2009. No heavy rain events occurred during April and May, 2009. These two sets of hydrological data were then analyzed to show the merits of the HHT for decomposing water stage and components analysis in an estuary. 


\section{FACTORS AFFECTING THE WATER STAGES IN THE TANSHUI RIVER ESTUARY}

The HHT analysis included water stage data for the Chung Cheng Bridge collected from 10/01/2009 - 12/17/2009 and from 4/08/2009 - 5/28/2009. The hourly water stages were divided into seven IMF components, $C_{1}-C_{7}$, and a residual value $R(t)$. Table 2 shows the frequency, power (energy percentage) and inferred factors of each IMF.

In Fig. 5 and Table 2, from the graphical trend comparison and the IMF frequency with those of the collected hydrological data, the IMF $C_{1}$ frequency from 12:00 10/01/2009 - 23:00 $12 / 17 / 2009$ is $0.1792 \mathrm{~Hz}$ with a power of $2.46 \%$, and the IMF $C_{1}$ frequency from 03:00 4/08/2009 - 19:00 $5 / 28 / 2009$ is $0.192 \mathrm{~Hz}$ with a power of $2.18 \%$. Figure $5 \mathrm{a}$ shows that the waveform does not correlate with the water stage. The results of Huang et al. (1998) also indicated the IMF independence. Thus, physical phenomena assumedly has a relatively consistent effect because the water stage data frequencies in the two different time periods resemble the tidal frequency of lunar quarter constituent M4 or S4, as shown in Table 3. However, the major tidal type is the Mseries in the Taiwan Strait and the M4 is transformed from M2 tidal (Chiou et al. 2004; Jan et al. 2004). Therefore, the IMF $C_{1}$ should be a large lunar quarter constituent M4.

The frequency of the second component, IMF $C_{2}$, is $0.0805 \mathrm{~Hz}$ with a power of $81.50 \%$ at $12: 0010 / 01 / 2009$ - 23:00 12/17/2009. The IMF $C_{2}$ frequency from 03:00 $4 / 08 / 2009-19: 005 / 28 / 2009$ is $0.0810 \mathrm{~Hz}$ with a $92.60 \%$ power. The frequencies of IMF $C_{2}$ are isolated from the water stage in different time periods. The frequencies are similar. They are influenced by the stabilizing physical phenomena. Figure 6 compares the IMF waveforms and original water stage data. The IMF $C_{2}$ and IMF $C_{1}$ have the same characteristics. Their waveforms do not correlate with original water stage. Instead, they fluctuate regularly due to a regular influence, i.e., the frequency of IMF $C_{2}$ resembles that of the principle lunar semidiurnal constituent M2. M2 tide is influenced by the moon. The phase of the M2 constituents normally gives the time of high tide after the moon has passed through a particular meridian (Martin and McCutcheon 1999).

Figure 6 shows the time of the new moon, full moon, perigee and apogee with IMF $C_{2}$. At 6:28 4/28/2009, 3:45 05/26/2009, 7:57 9/16/2009, 12:29 10/13/2009, 07:31 $11 / 07 / 2009$, and $14: 1312 / 04 / 2009$ is perigee. At 9:17 04/16/2009, 2:58 05/14/2009, 23:19 10/25/2009, and 20:08 $11 / 22 / 2009$ is apogee. At 3:24 4/25/2009, $12: 125 / 24 / 2009$, 5:33 10/18/2009, 19:14 11/16/2009, and 12:03 12/16/2009 is a new moon. At 14:56 4/09/2009, 4:02 5/09/2009, 6:12 $10 / 04 / 2009,19: 1511 / 02 / 2009$, and 07:32 12/02/2009 is full moon. There is a high flow event in Fig. 6a. Therefore, it is difficult to observe the reaction between the moon and IMF $C_{2}$ waveform. There is no high flow event in Fig. 6b. The waveform peak is near the perigee period in Fig. 6b. This result shows the interaction between M2 tide and changes of the moon from the research by Chen et al. (2013). The Taiwan Strait is dominated by the M2 tide. Table 3 shows the $\mathrm{M} 2$ tide frequency is very close to the IMF $C_{2}$ frequency. Therefore, IMF $C_{2}$ should be the principle lunar semidiurnal constituent M2.

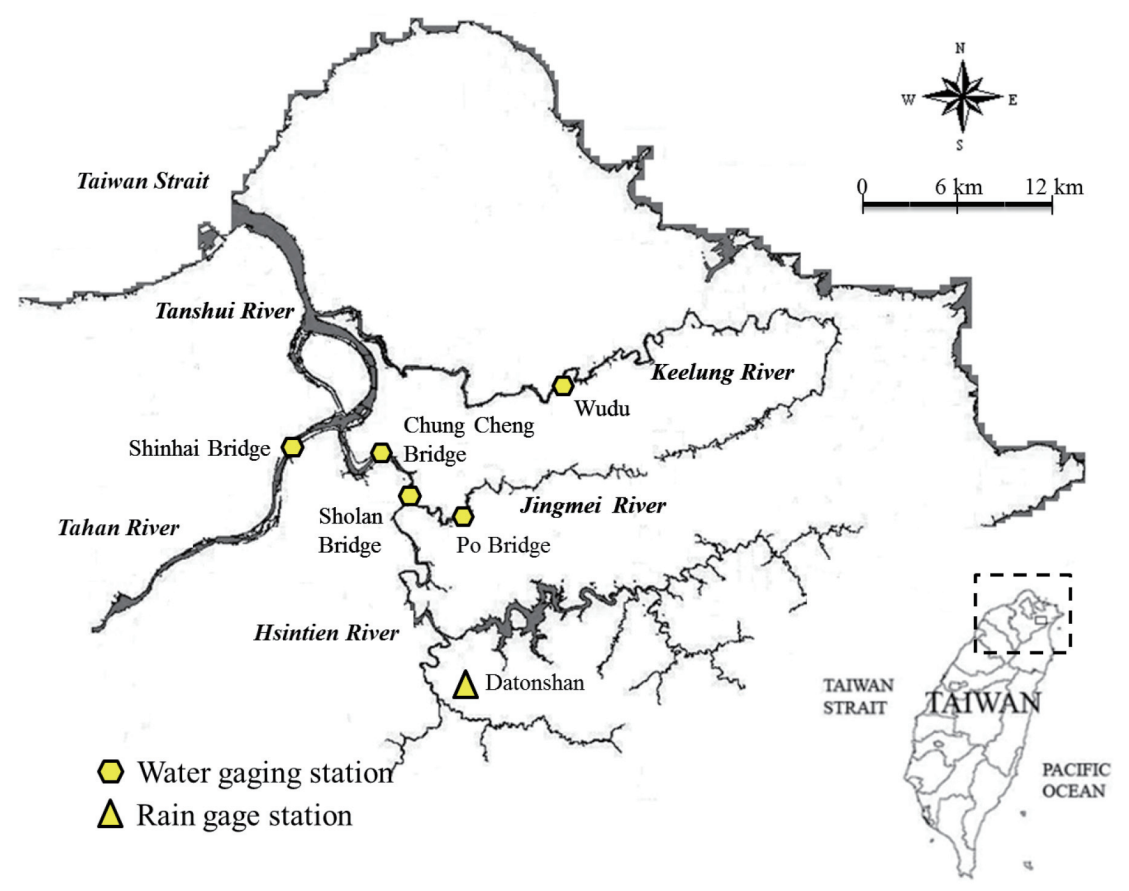

Fig. 4. Study Area and Hydrological Stations. 
Table 1. Statistical features of hydrological data.

\begin{tabular}{c|c|cc|c|c|c|c}
\hline \multicolumn{2}{l|}{} & \multicolumn{2}{|c|}{ Water stage (m) } & Rainfall (mm) & Temperature $\left({ }^{\circ} \mathbf{C}\right)$ & Pressure (hPa) & Humidity $(\%)$ \\
\cline { 3 - 8 } \multicolumn{2}{l|}{} & Chung Cheng Bridge & Po Bridge & Datonshan & Datonshan & Datonshan & Datonshan \\
\hline \multirow{4}{*}{$10 / 1 / 2009-12 / 17 / 2009$} & Mean & 0.43 & 7.61 & 0.70 & 20.52 & 1006.08 & 81.95 \\
& Std. Dev & 0.82 & 0.59 & 2.11 & 3.65 & 4.68 & 12.24 \\
& Max. & 2.97 & 13.07 & 31.00 & 32.10 & 1021.10 & 96.00 \\
& Min. & -1.29 & 7.18 & 0.00 & 10.00 & 995.30 & 42.00 \\
\hline \multirow{4}{*}{$4 / 8 / 2009-5 / 28 / 2009$} & Mean & 0.20 & 7.45 & 0.21 & 22.39 & 1001.78 & 73.53 \\
& Std. Dev & 0.77 & 0.34 & 1.78 & 4.11 & 3.39 & 16.20 \\
& Max. & 1.99 & 10.73 & 49.00 & 33.90 & 1010.30 & 93.00 \\
& Min. & -1.16 & 7.19 & 0.00 & 11.60 & 990.60 & 16.50 \\
\hline
\end{tabular}

Table 2. Factors affecting the water stages of the Tanshui River estuary at the Chung Cheng Bridge.

\begin{tabular}{c|cc|c}
\hline \multirow{2}{*}{ IMF } & \multicolumn{2}{|c|}{ Average Frequency (1/hour) // (Power \%) } & \multirow{2}{*}{ Inferred factors } \\
\cline { 2 - 3 } & $\mathbf{1 0 / 1 / 2 0 0 9 ~ - ~ 1 2 / 1 7 / 2 0 0 9}$ & $\mathbf{4 / 8 / 2 0 0 9 ~ - ~ 5 / 2 8 / 2 0 0 9}$ & $\mathrm{M} 4$ \\
\hline$C_{1}$ & $0.1792 / /(2.46 \%)$ & $0.1920 / /(2.18 \%)$ & $\mathrm{M} 2$ \\
$C_{2}$ & $0.0805 / /(81.50 \%)$ & $0.0810 / /(92.60 \%)$ & $\mathrm{K} 1$ \\
$C_{3}$ & $0.0425 / /(3.67 \%)$ & $0.0419 / /(4.30 \%)$ & Meteorological tide \\
$C_{4}$ & $0.0204 / /(2.65 \%)$ & $0.0231 / /(0.29 \%)$ & Discharge from the Upstream basin (Jingmei River) \\
$C_{5}$ & $0.0122 / /(0.51 \%)$ & $0.0120 / /(0.32 \%)$ & Rainfall from Upstream basin (Datonshan Station) \\
$C_{6}$ & $0.0047 / /(5.22 \%)$ & $0.0048 / /(0.15 \%)$ & Base flow \\
$C_{7}$ & $0.0023 / /(4.00 \%)$ & $0.0024 / /(0.16 \%)$ & Trend \\
$R$ & -- & -- &
\end{tabular}
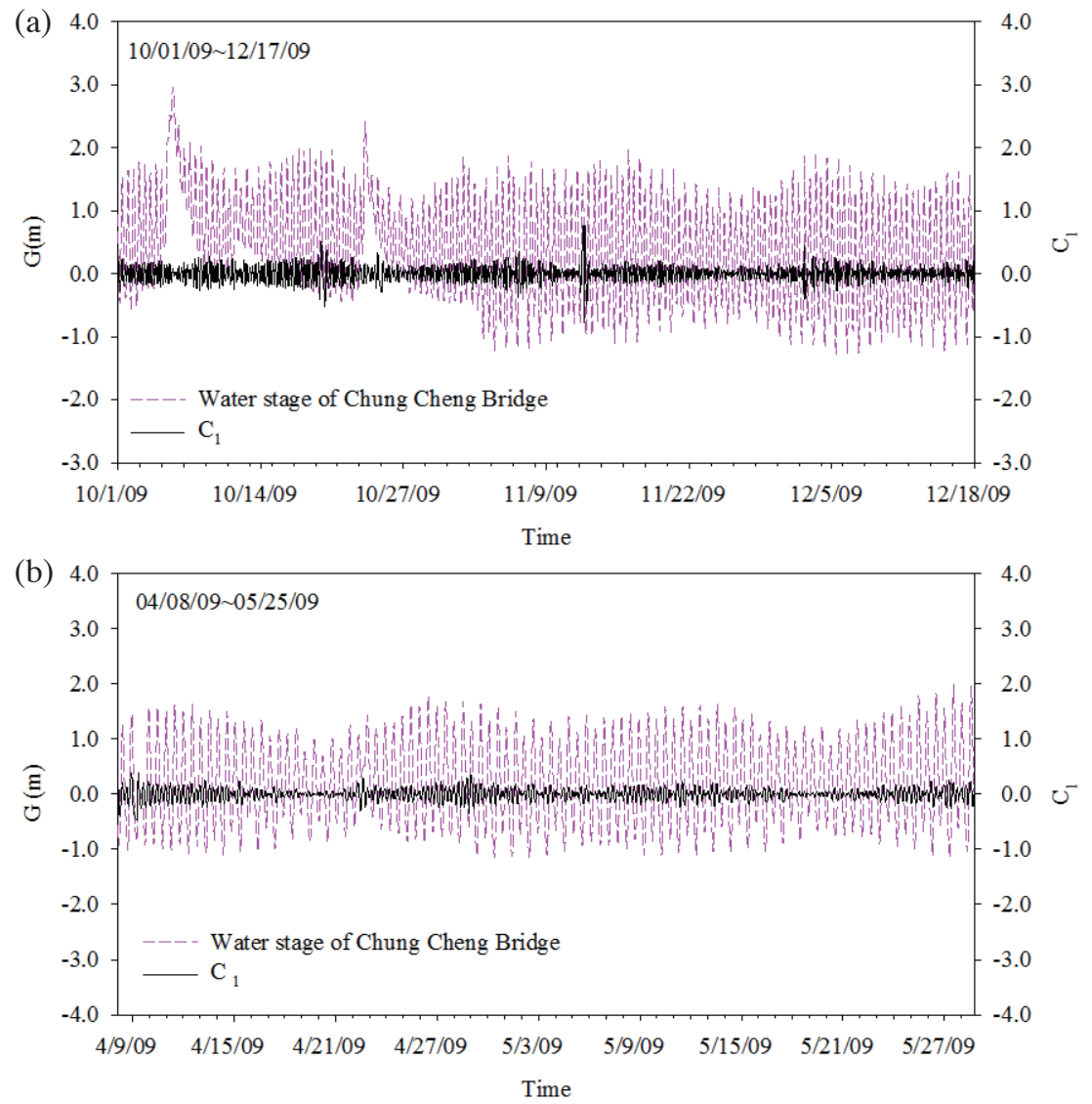

Fig. 5. The water stage and IMF component $C_{1}$ of the Tanshui River estuary at the Chung Cheng Bridge; (a) 0:00 10/1/2009 - 23:00 12/17/2009; (b) 3:00 4/8/2009 - 19:00 5/25/2009. 
Table 3. The classical tidal types.

\begin{tabular}{c|cccc}
\hline Type & Characterizes & Name & Cycle (hour/cycle) & Frequency \\
\hline \multirow{5}{*}{ Semi-diurnal tides } & $\mathrm{K}_{2}$ & Lunisolar diurnal constituent & 11.9672 & 0.0836 \\
& $\mathrm{~S}_{2}$ & Principal solar semidiurnal constituent & 12.0000 & 0.0833 \\
& $\mathrm{M}_{2}$ & Principal lunar semidiurnal constituent & 12.4206 & 0.0805 \\
& $\mathrm{~N}_{2}$ & Large lunar elliptic semidiurnal constituent & 12.6583 & 0.0775 \\
& $2 \mathrm{~N}_{2}$ & Second large lunar elliptic semidiurnal constituent & 12.9054 & 0.0790 \\
\hline \multirow{5}{*}{ Diurnal tides } & $\mathrm{K}_{1}$ & Lunisolar diurnal constituent & 23.9345 & 0.0418 \\
& $\mathrm{P}_{1}$ & Principal solar diurnal constituent & 24.0659 & 0.0416 \\
& $\mathrm{O}_{1}$ & Principal lunar diurnal constituent & 25.8193 & 0.0387 \\
& $\mathrm{Q}_{1}$ & Large lunar elliptic constituent & 26.8684 & 0.0372 \\
\hline \multirow{3}{*}{ Overtides } & $\mathrm{S}_{4}$ & Solar quarter constituent & 6.0000 & 0.1667 \\
& $\mathrm{M}_{4}$ & Large lunar quarter constituent & 6.2103 & 0.1610 \\
\hline
\end{tabular}
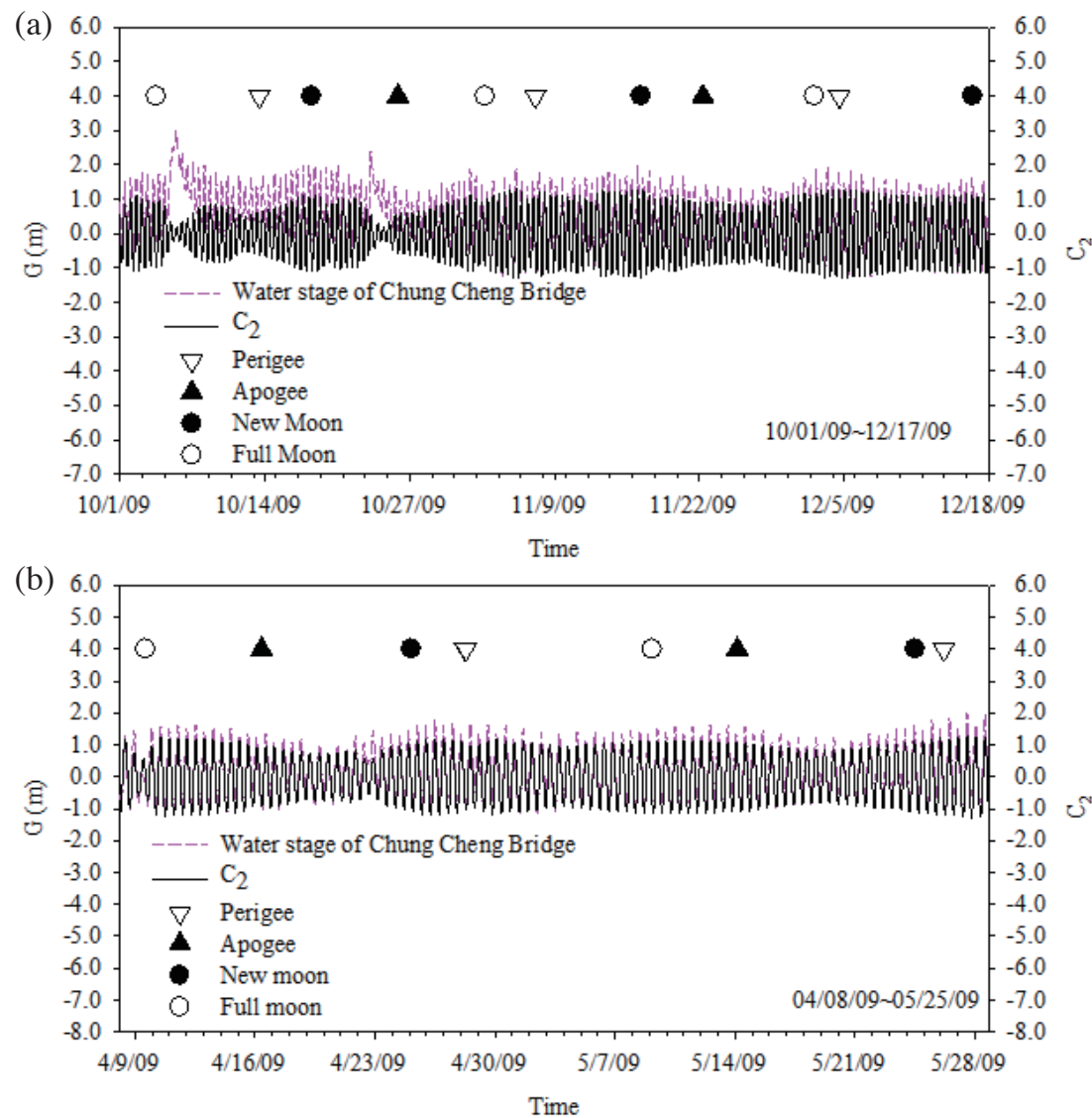

Fig. 6. The water stage and IMF component $C_{2}$ of the Tanshui River estuary at the Chung Cheng Bridge; (a) 0:00 10/1/2009 - 23:00 12/17/2009; (b) 3:00 4/8/2009 - 19:00 5/25/2009.

In Fig. 7, the IMF waveforms are compared to the original water stages, showing that the IMF waveforms did not correlate with the water stage. Therefore, we believe that the IMF- $C_{3}$ is affected by a natural phenomenon whose scale is larger than typhoon or storm events. The tidal and IMF frequency comparisons show that the IMF frequencies at two periods are close to the lunisolar diurnal constituent $\mathrm{K} 1$ frequency. The IMF $C_{3}$ frequency is $0.0425 \mathrm{~Hz}$ during 10/01/2009 - 12/18/2009 and $0.0419 \mathrm{~Hz}$ during 4/08/2009 $5 / 28 / 2009$. There is no severe flood event during the period. The frequency of components is much closer to $\mathrm{K} 1$ tide as shown in Table 3 . Thus, the IMF $C_{3}$ component should be 

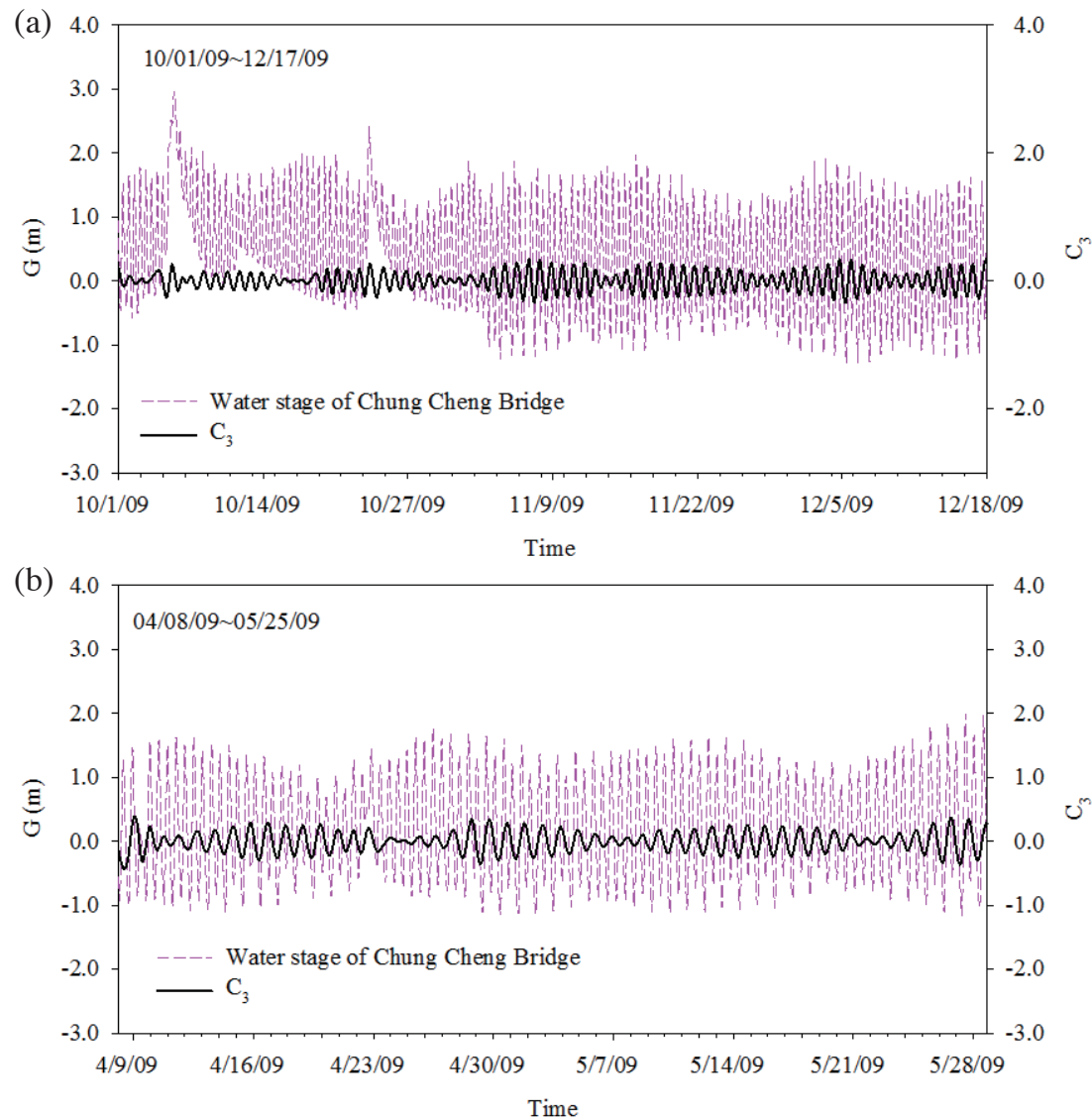

Fig. 7. The water stage and IMF component $C_{3}$ of the Tanshui River estuary at the Chung Cheng Bridge; (a) 0:00 10/1/2009 - 23:00 12/17/2009; (b) 3:00 4/8/2009 - 19:00 5/25/2009.

the $\mathrm{K} 1$ tide. These data indicate that IMF $C_{2}$, and IMF $C_{3}$ should be from astronomical tides.

The cycle time for the fourth IMF component IMF $C_{4}$ has two periods from $43-49$ hrs (Fig. 8). The Comparison in Fig. 7 clearly shows that the IMF $C_{4}$ waveform, although subject to the influence of changes in the original water stage, maintains a certain periodicity. Figure 8a is the comparison of IMF $C_{4}$ and the original water stage between $10 / 01 / 2009$ to $12 / 17 / 2009$. The IMF $C_{4}$ peaks occurred at 07:00 10/03/2009, 00:00 10/06/2009, and 16:00 $10 / 23 / 2009$. The water stage peaks at the Chung Cheng Bridge occurred at 00:00 10/06/2009, 11:00 10/17/2009, and 16:00 10/23/2009. Basically, both IMF $C_{4}$ peaks and the water stage at the Chung Cheng Bridge occurred simultaneously. The same phenomenon also can be found in Fig. $8 \mathrm{~b}$. Restated, IMF $C_{4}$ should be affected by factors that produce changes in the water stage in an estuary, ocean tides and freshwater discharge.

When the atmospheric pressure is low, the sea level tends to be higher than normal. Those influence results on the water stage is called meteorological effects or meteorological tide (CWB 2017; NGA 2017). Due to the low atmospheric pressure and speedy wind, the meteorological tide has an immediate reaction to the water level during a typhoon.
The IMF $C_{4}$ power was $2.65 \%$ during the typhoon event period and $0.29 \%$ without typhoon events. Comparisons between the IMFs power during the typhoon period and without typhoon period are shown Table 2 . The powers during the two periods are drastically different. Furthermore, the IMF $C_{4}$ waveform, as shown in Fig. 8a, has dramatic changes at the first and second typhoon events. The IMF $C_{4}$ peak and the water stage height occur at the same time during the typhoon events. According to the results, the IMF $C_{4}$ met the characteristics of the meteorological tide. Therefore, we considered the IMF $C_{4}$ is meteorological tide.

Figure 9 illustrates the changes in waveforms in two different periods. The IMF waveform does not appear periodically, without significant changes until the water stage fluctuated at the Po Bridge Station. The flood events on 10/1/2009 and 12/17/2009 clearly show that the IMF waveform change depends on variations in the Po Bridge water stage. As shown in Fig. 9a, the peak water stage time at the Po Bridge approached that of IMF $C_{5}$ during Typhoon Parma (10/03/2009 - 10/07/2009) and during Typhoon Lupit (10/13/2009 10/27/2009). The water stage comparisons for the Po Bridge and IMF $C_{5}$ during 4/08/2009 - 5/28/2009 demonstrate the hydrography and IMF $C_{5}$ peaks occurring simultaneously. As shown in Fig. 9b, the peak in the hydrograph at the Po 

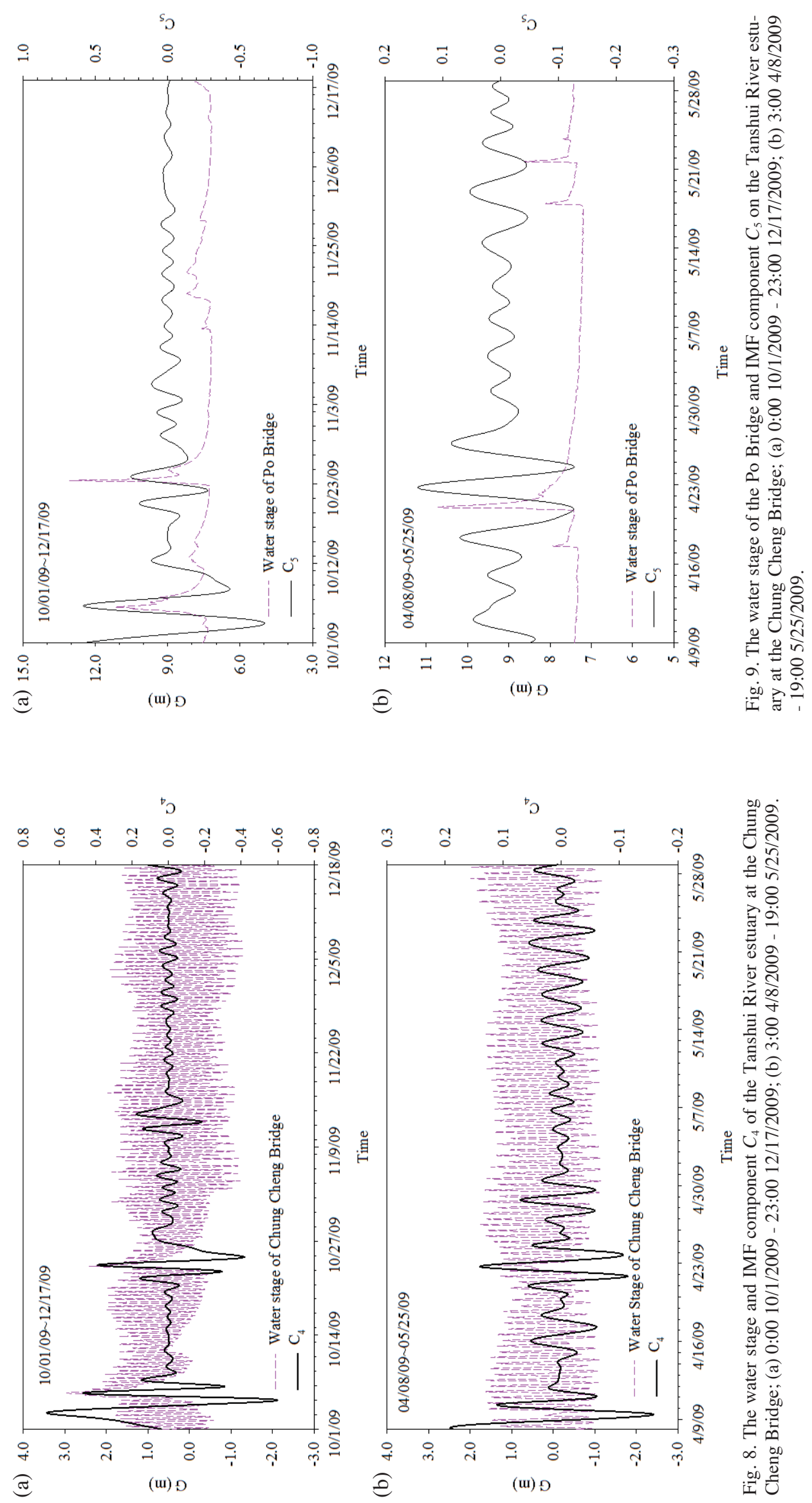
Bridge occurred during Typhoon Lupit (10/21/2009) with fluctuations subject to the water stage. As shown in Fig. 4, the Po Bridge is located in the Jingmei River, which is the major tributary of the Hsintien River. Figure 8 reveals that the waveform trend and IMF $C_{5}$ peaks in two periods conform to the water stage changes at the Po Bridge. Therefore, the IMF $C_{5}$ can be used to represent the discharge effect from an upstream tributary on the main stream water stage.

In Fig. 10, the Datonshan rain gage station rainfall data was compared with the 6th IMF $C_{6}$. As shown in Fig. 4, Datonshan rain gage station, located at the Nanshih River catchment, is a major tributary of the Hsintien River. Figure 10a shows that the trends in rainfall peaks during Typhoon Parma and Typhoon Lupit conform to those of the IMF $C_{6}$. Although heavy rain events occurred during 03:00 11/01/2009 - 10:00 11/02/2009 and 16:00 12/06/2009 - 15:00 12/15/2009, the peak trends can only be determined during Typhoon Parma and Typhoon Lupit, due to the lack of rainfall data. Figure 10b shows that the rainfall recorded at Datonshan and IMF $C_{6}$ component during 03:00 4/08/2009 - 19:00 5/28/2009 are similar to that given in Fig. 10a. The IMF waveform peak occurs after a heavy rainfall, which is similar to the rainfall-runoff process concentration time. Hence, IMF $C_{6}$ results from the rainfall at Datonshan. In other words, the IMF $C_{6}$ is caused by the most upstream flow in the Hsintien River; thus, the IMF $C_{5}$ and IMF $C_{6}$ are upstream discharge influences in the Hsintien River. Those IMF $C_{5}$ and IMF $C_{6}$ inferences confirm Dyer's research in 1973 that the storms and river events contribute significantly to the estuary water stage (Dyer 1973).

The data were collected at different locations, but in the Tanshui River estuary catchment these different locations are connected by the watershed channel and overland flow. We found that IMF $C_{5}$ and IMF $C_{6}$ are apparently affected by the previous hydrological phenomenon in the study site upstream. The occurrences of peaks in IMFs are always behind the peaks found in the discharge hydrograph and rainfall hyetographs at gages in the study site upstream. So the time difference between the peaks indicated the relevance of distance demonstrated the surface hydrological description for the Lag-time. Therefore, we believed the IMF $C_{5}$ and IMF $C_{6}$ are affected by surface hydrological phenomenon.

The seventh IMF component was set to IMF $C_{7}$, as shown in Fig. 11 with three hydrographs. There are water stages at different periods for the Chung Cheng Bridge $(\mathrm{G})$, IMF $C_{7}$ and $\left[G-\left(C_{1}+C_{2}+C_{3}+C_{4}\right)\right]$. The $\left[G-\left(C_{1}+C_{2}+C_{3}+\right.\right.$ $\left.\left.C_{4}\right)\right]$ is the water stage, excluding the ocean influence factors, which means it is caused by the terrestrial water. In Fig. 11, the $\left[G-\left(C_{1}+C_{2}+C_{3}+C_{4}\right)\right]$ is affected by short termed changes in scale. We picked high water stage events, as
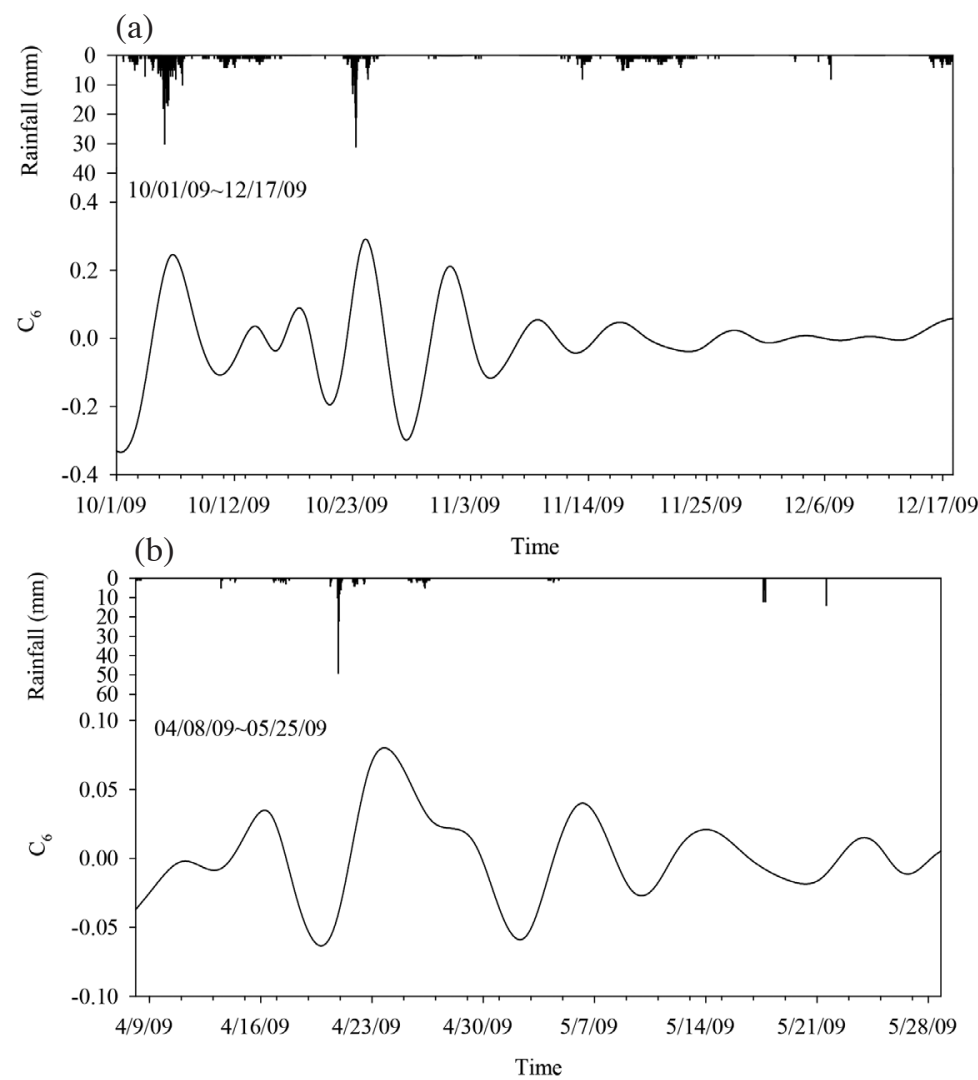

Fig. 10. The rainfall of Datonshan and $C_{6}$ of the Tanshui River estuary at the Chung Cheng Bridge; (a) 0:00 10/1/2009 - 23:00 12/17/2009; (b) 3:00 4/8/2009 - 19:00 05/25/2009. 

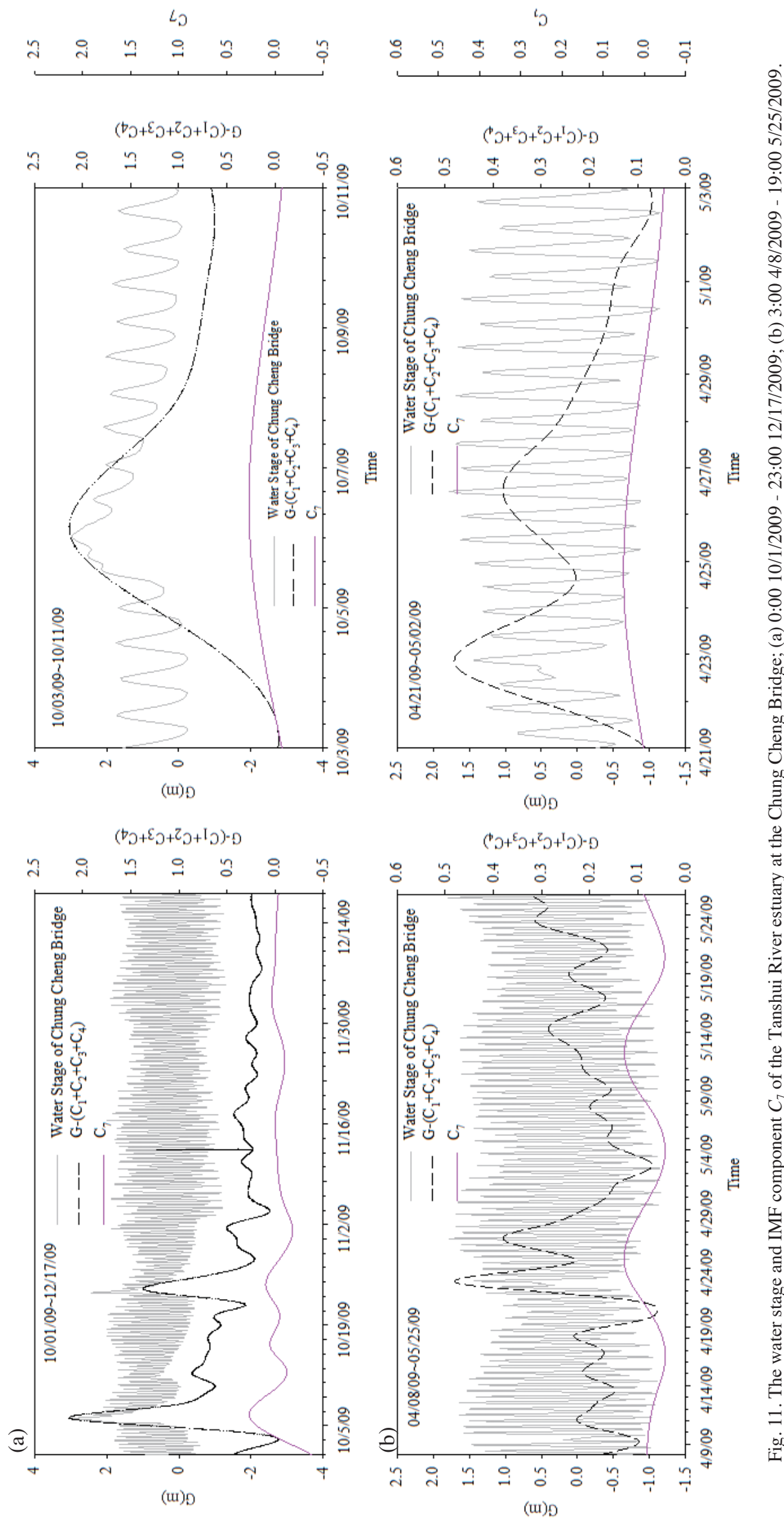

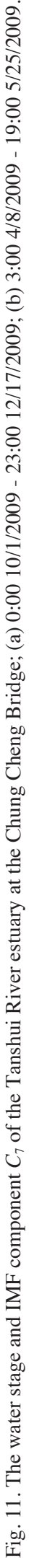


shown in Figs. 11a and b. The $\left[G-\left(C_{1}+C_{2}+C_{3}+C_{4}\right)\right]$ has a rising limb from 08:00 10/03/2009 - 06:00 10/05/2009, a peak from 06:00 10/05/2009 - 16:00 10/06/2009 and a recession limb from 16:00 10/06/2009 - 05:00 10/08/2009. The IMF $C_{7}$ shows stability and smoothness is unaffected by short termed changes in scale. There are similar results to the graphical, hydrometric-based separation of storm hydrograph. Besides, we chose high water stage events from 4/21/2009-5/03/2009. The $\left[G-\left(C_{1}+C_{2}+C_{3}+C_{4}\right)\right]$ had peaks at 21:00 4/22/2009 and 18:00 4/26/2009, which are similar. Patra (2001) defined a base flow as "part of stream flow available mainly from ground water reservoir and delayed subsurface flow appearing during the dry period". The base flow hydrograph shows a smooth curve, that is unaffected by short termed changes in scale. Based on the assumption that the water stage has a positive correlation to the discharge, the IMF $C_{7}$ curve is representative for the base flow features.

Figure 12 shows the residual value $R(t)$, in which, the residual waveforms modifications $R(t)$ at two periods alter along with the varied trend of the overall water level. The flow condition of gradually varied flow shows a consistency between the water stage and discharge. The $R(t)$ is the trend of water stage.
The above results show that the water stage components in the study area could be divided into three major characteristics. First, the influences of tides (ocean), which are composed of M4 partial tide, M2 partial tide and K1 partial tide, and represented by IMF $C_{1}$, IMF $C_{2}$, and IMF $C_{3}$ respectively. Secondly, the interactive influences of surface water and atmospheric phenomena, in which IMF $C_{4}$ is taken as the transforming interface representing both. Finally, influences from the upstream flow of an estuary, i.e., upstream river discharge, rainfall and Base Flow. It is represented on the signal features of IMF $C_{5}$, IMF $C_{6}$ and IMF $C_{7}$ respectively.

Those IMFs were analyzed with HHT to obtain the evolution tendency from high frequency to low frequency. The ocean influences IMF $C_{1}$, IMF $C_{2}$, and IMF $C_{3}$ are high frequencies, evolving to low frequency parts gradually due to the IMF $C_{5}$, IMF $C_{6}$, and IMF $C_{7}$ influenced by the terrestrial water.

Furthermore, comparing high flow events in 10/01/2009 - 12/17/2009 with normal flow events in 4/08/2009 $5 / 28 / 2009$, the power of factors takes the Principal lunar semidiurnal M2 constituent as the highest proportion of influences, regardless whether there is a high flow event. In
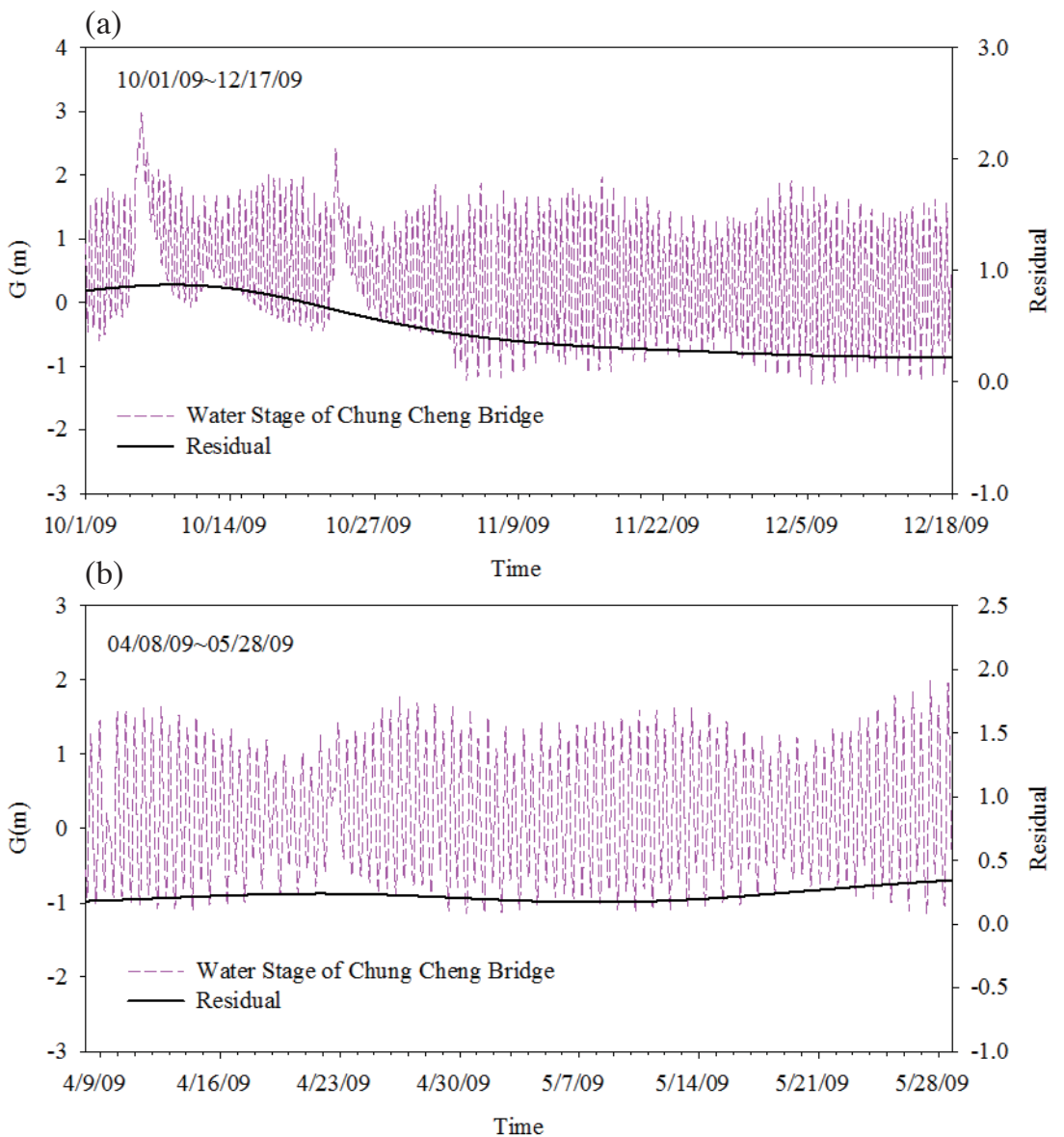

Fig. 12. The water stage and residual of the Tanshui River estuary at the Chung Cheng Bridge; (a) 0:00 10/1/2009 - 23:00 12/17/2009; (b) 3:00 4/8/2009 - 19:00 5/25/2009. 
either case, the influence degree (power) of the tides is more than $80 \%$ in the Chung Cheng Bridge.

\section{CONCLUSIONS}

This study proposes a specific method for conceptualizing hydrological processes in an estuary. The results reveal that the factors affecting water stages in an estuary can be classified as marine and terrestrial factors. The marine factors include the lunar quarter constituent M4, the Principal lunar semidiurnal constituent M2, and the lunisolar diurnal constituent $\mathrm{K} 1$ factors representing the effects of a river include the upstream branch discharge, rainfall, and base flow. Comparing the power of components, the power summary of ocean tides to the water stage components exceeded $80 \%$ in the studied estuaries. That is, the data indicated that the main factor in the water stage is marine tides in the study area.

This study used a reliable and easy to use method based on the Empirical Mode Decomposition and Hilbert transform, which provides the orthogonality and completely decomposed results. During the analysis process, the interference between each hydrological factor could be reduced. Researchers could estimate the initial values based on decomposed results before performing more accurate numerical simulations or field experiments. This approach reveals the specific experiments needed and improved precision, which reduces the costs of related researches. The results prove the former research results in estuaries but also provide a visualized evidence of water stage component factors in estuaries. Therefore, researchers could provide visualized evidences in every component factor for the hydrological processes in an estuary to the public's understanding.

Acknowledgements The authors would like to thank the Ministry of Science and Technology, Taiwan for financially/partially supporting this research under Grant no. MOST 106-2221-E-027-031.

\section{REFERENCES}

Chen, Y. C., T. M. Yang, N. S. Hsu, and T. M. Kuo, 2012: Real-time discharge measurement in tidal streams by an index velocity. Environ. Monit. Assess., 184, 64236436, doi: 10.1007/s10661-011-2430-y. [Link]

Chen, Y. C., S. P. Kao, and H. W. Chiang, 2013: Defining an estuary using the Hilbert-Huang transform. Hydrolog. Sci. J., 58, 841-853, doi: 10.1080/02626667.2013.779776. [Link]

Chen, Y. C., S. P. Kao, and J. H. Wu, 2014: Measurement of stream cross section using ground penetration radar with Hilbert-Huang transform. Hydrol. Process., 28, 2468-2477, doi: 10.1002/hyp.9755. [Link]

Chiou, M.-D., T.-C. Huang, C.-C. Kao, and C.-H. Wu, 2004: The characteristics of shallow water tidal constituents in Taiwan Strait. Proceedings of the 26th Ocean Engineering Conference, Taipei, Taiwan.

CWB, 2017: Introduction of Typhoon Surge Wave, Minister of Transportation and Communication R.O.C, Central Weather Bureau, Taiwan.

Dyer, K. R., 1973: Estuaries: A Physical Introduction, Wiley, Chichester, $195 \mathrm{pp}$.

El-Jabi, N., G. Wakim, and S. Sarraf, 1992: Stage-discharge relationship in tidal rivers. J. Wtrwy., Port, Coast., and Oc. Engrg., 118, 166-174, doi: 10.1061/(asce)0733950x(1992)118:2(166). [Link]

Elliott, M. and D. S. McLusky, 2002: The need for definitions in understanding estuaries. Estuar. Coast. Shelf Sci., 55, 815-827, doi: 10.1006/ecss.2002.1031. [Link]

Ganju, N. K., M. Hayn, S.-N. Chen, R. W. Howarth, P. J. Dickhudt, A. L. Aretxabaleta, and R. Marino, 2012: Tidal and groundwater fluxes to a shallow, microtidal estuary: constraining inputs through field observations and hydrodynamic modeling. Estuaries Coasts, 35, 1285-1298, doi: 10.1007/s12237-012-9515-x. [Link]

Godin, G., 1985: Modification of river tides by the discharge. J. Wtrwy., Port, Coast., and Oc. Engrg., 111, 257275, doi: 10.1061/(asce)0733-950x(1985)111:2(257). [Link]

Huang, N. E. and N. O. Attoh-Okine, 2005: The HilbertHuang Transform in Engineering, CRC Press, 328 pp.

Huang, N. E. and S. S. P. Shen, 2014: Hilbert-Huang Transform and Its Applications, World Scientific, Singapore, $386 \mathrm{pp}$.

Huang, N. E. and Z. Wu, 2008: A review on Hilbert-Huang transform: Method and its applications to geophysical studies.Rev.Geophys.,46, doi: 10.1029/2007rg000228. [Link]

Huang, N. E., Z. Shen, S. R. Long, M. C. Wu, H. H. Shih, Q. Zheng, N.-C. Yen, C.C. Tung, and H. H. Liu, 1998: The empirical mode decomposition and the Hilbert spectrum for nonlinear and non-stationary time series analysis. Proc. Math. Phys. Eng. Sci., 454, 903-995, doi: 10.1098/rspa.1998.0193. [Link]

Huang, N. E., M.-L. Wu, W. Qu, S. R. Long, and S. S. P. Shen, 2003: Applications of Hilbert-Huang transform to non-stationary financial time series analysis. Appl. Stoch. Model. Bus. Ind., 19, 245-268, doi: 10.1002/ asmb.501. [Link]

Jan, S., C. S. Chern, J. Wang, and S. Y. Chao, 2004: The anomalous amplification of $\mathrm{M}_{2}$ tide in the Taiwan Strait. Geophys. Res. Lett., 31, doi: 10.1029/2003GL019373. [Link]

Liu, W.-C., 2005: Modeling the influence of settling velocity on cohesive sediment transport in Tanshui River estuary. Environ. Geol., 47, 535-546, doi: 10.1007/ s00254-004-1176-z. [Link]

Liu, W.-C. and W.-C. Huang, 2012: Modeling the transport and distribution of fecal coliform in a tidal estuary. 
Sci. Total Environ., 431, 1-8, doi: 10.1016/j.scitotenv.2012.05.016. [Link]

Lu, M. M., Y. M. Cho, Y. C. Lin, and N. E. Huang, 2016: Atlantic and Pacific multidecadal variability influence on Taiwan winter temperature centennial trend during the period 1911 - 2010. Terr. Atmos. Ocean. Sci., 27, 605-615, doi: 10.3319/TAO.2016.06.30.02. [Link]

Marcelo Acha, E., H. Mianzan, R. Guerrero, J. Carreto, D. Giberto, N. Montoya, and M. Carignan, 2008: An overview of physical and ecological processes in the Rio de la Plata Estuary. Cont. Shelf Res., 28, 1579-1588, doi: 10.1016/j.csr.2007.01.031. [Link]

Martin, J. L. and S. C. McCutcheon, 1999: Hydrodynamics and Transport for Water Quality Modeling, Lewis Publishers, Roca Raton, 192 pp.

Meccia, V.L.,C.G. Simionato, M.E.Fiore,E.E.D'Onofrio, and W. C. Dragani, 2009: Sea surface height variability in the Rio de la Plata estuary from synoptic to inter-annual scales: Results of numerical simulations. Estuar. Coast. Shelf Sci., 85, 327-343, doi: 10.1016/j. ecss.2009.08.024. [Link]

NGA, 2017: Tides and Tidal Currents, United States Department of Defense, National Geospatial-Intelligence Agency, Virginia, $22 \mathrm{pp}$.

Null, K. A., N. T. Dimova, K. L. Knee, B. K. Esser, P. W. Swarzenski, M. J. Singleton, M. Stacey, and A. Paytan, 2012: Submarine Groundwater Discharge-Derived Nutrient Loads to San Francisco Bay: Implications to Future Ecosystem Changes. Estuaries Coasts, 35, 1299-1315, doi: 10.1007/s12237-012-9526-7. [Link]

O'Callaghan, J. M., 2004: Tidal and Sediment Dynamics of a Partially Mixed Micro-tidal Estuary, Doctoral thesis, University of Western Australia, Perth, Australia.

Patra, K. C., 2001: Hydrology and Water Resources Engineering, Alpha Science International, Oxford, $591 \mathrm{pp}$.

Prandle, D., 2004: Saline intrusion in partially mixed estuaries. Estuar. Coast. Shelf Sci., 59, 385-397, doi: 10.1016/j.ecss.2003.10.001. [Link]

Pritchard, D. W., 1967: What is an estuary: physical viewpoint. In: Lauf, G. H. (Ed.), Estuaries, American Association for the Advancement of Science, Washington, DC. 3-5.

Pugh, D. T., 1996: Tides, Surges and Mean Sea-Level, John Wiley \& Sons, New York, 472 pp.

Rao, A. R. and E.-C. Hsu, 2008: Hilbert-Huang Transform Analysis of Hydrological and Environmental Time Series, Springer, Dordrecht, 239 pp, doi: 10.1007/978-14020-6454-8. [Link]

Rilling, G., P. Flandrin, and P. Goncalves, 2003: On empirical mode decomposition and its algorithms. IEEEEURASIP Workshop on nonlinear Signal and Image Processing, Vol. 3, IEEER, Grado, Italy.

Shaha, D. C., Y. K. Cho, T. W. Kim, and A. Valle Levinson, 2012: Spatio-temporal variation of flushing time in the Sumjin River Estuary. Terr. Atmos. Ocean. Sci., 23, 119-130, doi: 10.3319/TAO.2011.08.22.01(Hy). [Link]

Thain, R. H., A. D. Priestley, and M. A. Davidson, 2004: The formation of a tidal intrusion front at the mouth of a macrotidal, partially mixed estuary: A field study of the Dart estuary, UK. Estuar. Coast. Shelf Sci., 61, 161-172, doi: 10.1016/j.ecss.2004.04.012. [Link]

Vandenbohede, A., L. Lebbe, S. Gysens, K. Delecluyse, and P. DeWolf, 2008: Salt water infiltration in two artificial sea inlets in the Belgian dune area. J. Hydrol., 360, 77-86, doi: 10.1016/j.jhydrol.2008.07.018. [Link]

Yan, R. and R. X. Gao, 2006: Hilbert-Huang TransformBased Vibration Signal Analysis for Machine Health Monitoring. IEEE Trans. Instrum. Meas., 55, 23202329, doi: 10.1109/TIM.2006.887042. [Link]

Zeldis, J., C. Howard Williams, C. Carter, and D. Schiel, 2008: ENSO and riverine control of nutrient loading, phytoplankton biomass and mussel aquaculture yield in Pelorus Sound, New Zealand. Mar. Ecol.Prog.Ser., 371, 131-142, doi: 10.3354/meps07668. [Link] 